University of Nebraska - Lincoln

DigitalCommons@University of Nebraska - Lincoln

USDA National Wildlife Research Center - Staff Publications
U.S. Department of Agriculture: Animal and Plant Health Inspection Service

2011

\title{
Efficacy of GnRH Immunocontraception of Wild White-Tailed Deer in New Jersey
}

James P. Gionfriddo

USDA/APHIS/Wildlife Services' National Wildlife Research Center, james.p.gionfriddo@aphis.usda.gov

Anthony J. DeNicola

White Buffalo, Inc.

Lowell A. Miller

USDA/APHIS/Wildlife Services' National Wildlife Research Center, Fort Collins, CO, lowell.a.miller@aphis.usda.gov

Kathleen A. Fagerstone

USDA-APHIS National Wildlife Research Center, Fort Collins, kathleen.a.fagerstone@aphis.usda.gov

Follow this and additional works at: https://digitalcommons.unl.edu/icwdm_usdanwrc

Gionfriddo, James P.; DeNicola, Anthony J.; Miller, Lowell A.; and Fagerstone, Kathleen A., "Efficacy of GnRH Immunocontraception of Wild White-Tailed Deer in New Jersey" (2011). USDA National Wildlife Research Center - Staff Publications. 1320.

https://digitalcommons.unl.edu/icwdm_usdanwrc/1320

This Article is brought to you for free and open access by the U.S. Department of Agriculture: Animal and Plant Health Inspection Service at DigitalCommons@University of Nebraska - Lincoln. It has been accepted for inclusion in USDA National Wildlife Research Center - Staff Publications by an authorized administrator of DigitalCommons@University of Nebraska - Lincoln. 


\title{
Efficacy of GnRH Immunocontraception of Wild White-Tailed Deer in New Jersey
}

\author{
JAMES P. GIONFRIDDO, ${ }^{1}$ United States Department of Agriculture/Animal and Plant Health Inspection Service/Wildlife Services, \\ National Wildlife Research Center, 4101 LaPorte Avenue, Fort Collins, CO 80521, USA \\ ANTHONY J. DENICOLA, White Buffalo, Incorporated, 26 Davison Road, Moodus, CT 06469, USA \\ LOWELL A. MILLER, United States Department of Agriculture/Animal and Plant Health Inspection Service/Wildlife Services, \\ National Wildlife Research Center, 4101 LaPorte Avenue, Fort Collins, CO 80521, USA \\ KATHLEEN A. FAGERSTONE, United States Department of Agriculture/Animal and Plant Health Inspection Service/Wildlife Services, \\ National Wildlife Research Center, 4101 LaPorte Avenue, Fort Collins, CO 80521, USA
}

\begin{abstract}
Safe and effective contraceptive agents are needed to manage overabundant populations of cervids in settings where traditional management methods such as hunting are prohibited or impractical. We used GonaCon ${ }^{\text {TM }}$ Immunocontraceptive Vaccine to reduce reproduction in individual white-tailed deer (Odocoileus virginianus) on a fully fenced corporate-office campus in suburban New Jersey, USA. In JulyAugust 2005, we captured, marked, injected, and released 47 adult females and then monitored their reproductive performance for 2 years. Thirty-two of these females each received a $1.0-\mathrm{mL}$ injection of GonaCon vaccine, and 15 control females were given sham injections. Field observations of udder condition during summers of 2006 and 2007 were used to determine which adult female deer were lactating; lactation was used as an indicator of imminent or recent parturition. During summer 2006, 8 of 24 GonaCon-treated deer were pregnant, in contrast to 12 of 13 control deer. During summer 2007, 2 years after injections were given, 13 of 23 GonaCon-treated and 10 of 12 control animals were pregnant. We also captured, vaccinated, and released fawns (both sexes) and yearling and adult males and then monitored their reproductive status. Immunocontraception of fawns was unsuccessful. In some GonaCon-treated males (all age classes), serum testosterone concentrations and development of testes and antlers were reduced. Higher anti-gonadotropinreleasing-hormone antibody titers were associated with greater infertility in females and with lower values for reproductive parameters in males. GonaCon reduced reproduction in wild adult female white-tailed deer, but greater contraceptive efficacy may be required for it to gain widespread acceptance and use by natural resource managers. (c) 2011 The Wildlife Society.
\end{abstract}

KEY WORDS contraception, gonadotropin-releasing hormone, infertility, Odocoileus virginianus, overabundance.

Local populations of white-tailed deer (Odocoileus virginianus) have become overabundant in many regions of North America, where they are causing problems for residents and natural resource managers (Crête and Daigle 1999). Deermotor-vehicle collisions (Etter et al. 2000), severe overbrowsing of native and ornamental vegetation (Rooney and Waller 2003), and adverse effects on local avian communities (McShea and Rappole 2000) are among the problems caused by overabundant deer. Hunting is prohibited in many urban, suburban, and public park settings, and other deer management tools must be used. Contraception and other nonlethal deer management approaches are increasingly preferred by many urban and suburban residents (Stout et al. 1997, Lauber and Knuth 2000). Immunocontraception offers natural resource managers another tool to reduce

Received: 20 December 2010; Accepted: 4 April 2011

${ }^{1}$ E-mail: james.p.gionfriddo@aphis.usda.gov reproduction in overabundant wildlife populations (Fagerstone et al. 2002).

Although efforts to develop safe and effective wildlife contraceptive agents have been underway for about 50 years (Davis 1961, Vandenbergh and Davis 1962, Balser 1964), only 2 contraceptive products have been registered in the United States for wildlife: GonaCon ${ }^{\mathrm{TM}}$ Immunocontraceptive Vaccine (National Wildlife Research Center, Fort Collins, $\mathrm{CO})$ for adult female white-tailed deer, and a nicarbazinbased contraceptive bait ("OvoControl") for Canada Geese (Branta canadensis), certain domestic ducks, and pigeons (Columba livia; Innolytics, Rancho Santa Fe, CA). Among the obstacles to the development and registration of wildlife contraceptives is the achievement of objectives related to safety, efficacy, practicality, and humaneness of treatment. To be registered by the United States Environmental Protection Agency (EPA) and to gain widespread acceptance among wildlife management professionals, a contraceptive agent must: 1) not adversely affect the health, social behavior, or population structure of the target 
species; 2) not adversely affect nontarget species; 3) provide a complete, long-lasting (but ideally, reversible) contraceptive effect; 4) be cost-effective; and 5) not cause treated food animals to become unfit for human consumption (Fagerstone et al. 2010).

GonaCon Immunocontraceptive Vaccine is a gonadotropin-releasing hormone ( $\mathrm{GnRH})$-based wildlife contraceptive agent that has safely induced temporary infertility in many mammalian species (see refs in Gionfriddo et al. 2011). One intramuscular injection of GonaCon suppresses mammalian reproduction ( $\mathrm{M}$ or $\mathrm{F}$ ) for multiple years (Miller et al. 2004). GonaCon was registered with the United States EPA in September 2009 as a restricted-use product for the contraception of adult, female, white-tailed deer via hand injection (Fagerstone et al. 2010). Regarding potential risk associated with consuming deer treated with GonaCon vaccine, the EPA (Farwell 2009:2) has stated "There is little likelihood of exposure to hormonally active compound from deer meat because $\mathrm{GnRH}$ is a protein that is digested and not absorbed intact. Like other proteins, $\mathrm{GnRH}$ is too large and polar to pass through the membranes of the gastrointestinal tract. Proteins are digested into their component amino acids in the stomach and small intestines."

We tested GonaCon's contraceptive efficacy in whitetailed deer adults and fawns of both sexes. Adult females were the primary focus of the study because they will be the targets of real-world applications of GonaCon vaccine by natural resource managers. Fawns were tested to determine whether their immune systems were sufficiently mature to mount and maintain the strong immune responses to vaccination that are required to achieve and sustain a contraceptive effect. We also tested GonaCon in yearling and adult males. Although GonaCon is not registered or recommended for use in male deer (Killian et al. 2005, Curtis et al. 2008), deer-management field activities in North America often occur during winter when ambient temperatures are lower, deer are more visible (due to reduced vegetative cover), and deer occur in larger groups than at other times of year. Male deer lack antlers during late winter and can be mistaken for females. We vaccinated males to determine the effects of GonaCon treatment on male deer that might inadvertently be treated during winter management programs (if a $\mathrm{GnRH}$ vaccine is registered for remote injection or oral delivery in bait).

The objective of this 2-year field study was to evaluate the efficacy of GonaCon Immunocontraceptive Vaccine in individual wild white-tailed deer by determining the proportion of treated individuals that became infertile and the duration of induced infertility. For each year, we tested the hypothesis that pregnancy rates of adult females did not differ between GonaCon-treated and control deer. For male deer, we tested hypotheses to determine whether serum testosterone concentrations or testicular circumferences differed among treatment groups or age classes.

This research differs from our previous studies of GonaCon immunocontraception of white-tailed deer in several ways. Most studies involved captive deer at Pennsylvania State University where optimal diets and veterinary care (including de-worming) were routinely provided. In contrast, our field studies in Maryland, USA (Gionfriddo et al. 2009) and New Jersey, USA (Gionfriddo et al. 2011) involved wild deer subpopulations that lived independently of humans and ranged freely on very large, fenced, partially forested sites where forage was extremely overbrowsed, deer were exposed to natural environmental conditions, and deer received no veterinary care. Important differences between the Maryland and New Jersey field studies included the occupation of a single site by all study deer in New Jersey (GonaCon-treated and control deer occupied adjacent but different fenced sites in Maryland, for political and logistical reasons) and the injection of New Jersey control females with a sham material (controls in Maryland were not injected, again for political and logistical reasons). In addition, only adult female deer were tested in the Maryland study.

\section{STUDY AREA}

The study was conducted on a 123-ha corporate office campus near Madison, New Jersey, USA. Vegetation on the site consisted of hardwood forest (about 20\%), old fields in various stages of secondary succession (about 20\%), lawns (about 40\%), and landscaping near buildings. A 2.4-m-tall chain-link fence surrounded the property. Although the site was bounded by public roads on all 4 sides, public access to the campus was prohibited, and security gates and guards controlled access of authorized personnel. Despite the presence of the fence, a few deer entered or left the study area by running through gates opened briefly by guards for vehicular traffic. Most of the study area was accessible via a network of paved and gravel roads that was used during deer capture and observation activities. Limited food availability in forested areas caused deer to forage heavily on lawn areas where they were easily observed with binoculars and spotting telescopes. Long-term patterns of temperature and precipitation for the study area are summarized elsewhere (Gionfriddo et al. 2011).

\section{METHODS}

\section{Capture and Treatments}

General.-We captured deer at night with tranquilizer darts and fitted each animal with numbered ear tags and a radiotelemetry collar before reversing anesthesia and releasing deer at their capture sites, as described by Gionfriddo et al. (2011). We gave each deer a $1.0-\mathrm{mL}$ injection by hand to the deep musculature of the upper hind limb (see below); if a deer had been darted in a hind limb, we delivered the hand injection to the opposite hind limb. We observed all study deer during the summer(s) between their capture and October 2007, when deer were collected and necropsied.

Adult females.-During July and early August 2005, we captured all adult females $(n=47)$ present on the study area. We injected each female with GonaCon Immunocontraceptive Vaccine $(n=32$; each $1.0-\mathrm{mL}$ dose of GonaCon contained $1,000 \mu \mathrm{g}$ of conjugated $\mathrm{GnRH}$-hemocyanin in a water-inoil emulsion) or with a sham material $(n=15)$ that consisted of AdjuVac ${ }^{\text {TM }}$ adjuvant (National Wildlife Research 
Center) and mollusk stabilizing buffer (i.e., GonaCon vaccine without $\mathrm{GnRH}$ and without mollusk hemocyanin, which usually serves as a carrier molecule for the GnRH). We collected a blood sample from the jugular or femoral vein of each female for measurement of pretreatment serum anti$\mathrm{GnRH}$ antibody titers. Four GonaCon-treated adult females that became pregnant during autumn 2005 were recaptured in October 2006 and given a second vaccine injection to determine the effects of a booster dose on contraceptive efficacy. We assumed that these 4 females would (without boosting) have become pregnant during autumn 2006, and we classified them as pregnant for the 2007 efficacy analysis. Four other GonaCon-treated females were recaptured and reinjected with GonaCon in June 2007, after their reproductive status for spring 2007 had already been determined through observations of udder condition ( 1 of 4 had lactated in 2007; status was confirmed at necropsy).

Fawns and males.-To investigate the effects of GonaCon vaccination on young deer treated during their first winter, we captured, vaccinated, and released 8-month-old female fawns $(n=4)$ in February 2006. To determine whether GonaCon would elicit strong enough immune responses to induce infertility in 3-4-month-old fawns, and to establish the duration of such responses via evaluation of antibody titers, we captured fawns ( $8 \mathrm{~F}$ and $8 \mathrm{M}$ ) during SeptemberOctober 2006, vaccinated them with GonaCon, and released them. We captured, vaccinated, and released yearling $(n=3)$ and adult $(n=7)$ males during March 2007 to investigate the effects of wintertime vaccination with GonaCon on antibody and testosterone levels, testis size, and antler development in male white-tailed deer. Finally, to provide baseline data on untreated males, we collected previously uncaptured males (4 yearlings and 9 ad) during October 2007 for necropsy evaluation.

\section{Evaluation of Contraceptive Efficacy}

We evaluated the contraceptive efficacy of GonaCon vaccine in experimental female deer during 2006 and 2007 by using spring and summer field observations of udder condition in vaccinated and control deer to identify animals that were lactating. Lactation was used as an indicator of imminent parturition (i.e., current pregnancy) or recent pregnancy (Whitten 1995, Pojar and Bowden 2004, Gionfriddo et al. 2009). By repeatedly observing the udders of deer throughout the fawn-bearing and fawn-rearing seasons in 2006 and 2007, we were able to determine which individuals became pregnant, although we were unable to tell how many fawns were born to each female, or whether the fawn(s) survived. We used 1-tailed Fisher's exact tests $(\alpha=0.05$, $1 \mathrm{df}$ ) to compare, for each year, the proportion of GonaContreated females that lactated with the proportion of control females that lactated. The experimental unit was the individual deer.

Serum concentrations of anti-GnRH antibodies also can be used to assess immunocontraceptive efficacy (Miller et al. 2000). We used enzyme-linked immunosorbent assays (ELISAs) to measure serum antibody titers (Muller et al. 1997) in blood collected from vaccinated and control deer of both sexes at the conclusion of field activities in October 2007. We collected blood samples by cardiac puncture within 1 min of death after deer were shot in the head or neck with a high-powered rifle as they rested or foraged (no chase). We stored blood samples in a cooler or refrigerator until we isolated serum by centrifugation and shipped it to the National Wildlife Research Center in Fort Collins, Colorado, USA for analysis. An experienced wildlife veterinarian conducted field necropsies by following standard procedures described by Munson (2010). Examination of reproductive tracts during necropsy provided additional information on the reproductive status of study deer.

We investigated GonaCon's effects on reproductive status in male deer through necropsy observations and evaluation of blood serum in GonaCon-treated and noninjected control males. At necropsy in October 2007, we measured testicular circumferences to the nearest $0.5 \mathrm{~cm}$ and characterized the development of antlers (e.g., "buttons," "spikes," " $2 \times 2$ "). Later, we evaluated serum anti-GnRH antibody levels and testosterone concentrations via ELISAs. We then used 1tailed, 2 -sample $t$-tests $(\alpha=0.05)$ to compare mean testosterone levels and testicular circumferences of vaccinated and control males. All aspects of this research were approved by the Institutional Animal Care and Use Committee of the National Wildlife Research Center.

\section{RESULTS}

\section{Adult Females}

By June 2006, 8 of 32 GonaCon-treated and 2 of 15 control females had died or left the study site (Table 1). Field evaluations of udder condition were conducted during the summers of 2006 and 2007 by 2 independent observers. Because their conclusions were $100 \%$ in agreement when the same deer was studied $(n=55)$, the findings were considered conclusive when only one observer was able to

Table 1. Reproductive status of GonaCon-treated and control adult, female, white-tailed deer in New Jersey, USA, $2006-2007$.

\begin{tabular}{lccccccc}
\hline Treatment group & $\boldsymbol{n ( 2 0 0 5 )}$ & $\boldsymbol{n ( 2 0 0 6 ) ^ { \mathbf { a } }}$ & Pregnant (2006) & Not pregnant (2006) $^{\text {n(2007) }}$ & Pregnant (2007) $^{\mathbf{b}}$ Not pregnant (2007) \\
\hline GonaCon & 32 & 24 & $8(33 \%)^{\mathbf{c}}$ & $16(67 \%)$ & 23 & $13(57 \%)^{\mathrm{d}}$ & $10(43 \%)$ \\
Control & 15 & 13 & $12(92 \%)^{\mathrm{c}}$ & $1(8 \%)$ & 12 & $10(83 \%)^{\mathrm{d}}$ & $2(17 \%)$ \\
\hline
\end{tabular}

a By Jun 2006, 8 GonaCon-treated and 2 control deer were no longer on the study area. Three deer (2 GonaCon-treated and 1 control) had been killed by collisions with motor vehicles, and 5 (4 treated and 1 control) deer had died of unknown causes. In addition, 2 treated deer had apparently left the study area.

${ }^{\mathrm{b}}$ By Jun 2007, 2 additional deer (1 treated and 1 control) had died of unknown causes. The treated deer that died was 1 of the 2 treated deer (mentioned above) that had left the study area before summer 2006. The other treated deer that had left the study area could not be located in 2007. All 8 deer given booster vaccinations in Oct 2006 and Jun 2007 were included in the 2007 analysis (5 were pregnant).

${ }^{\mathrm{c}}$ Rates of pregnancy were higher in control $\mathrm{F}$ than in GonaCon-treated $\mathrm{F}$ during 2006 (Fisher's exact test, $P<0.001$ ).

${ }^{\mathrm{d}}$ Rates of pregnancy were not higher in control $\mathrm{F}$ than in GonaCon-treated $\mathrm{F}$ during 2007 (Fisher's exact test, $P=0.112$ ). 
study a deer $(n=14)$. During summer $2006,8(33 \%)$ of the 24 remaining vaccinated females and 12 (92\%) of the 13 control females lactated (Table 1). The pregnancy rate among control deer was nearly 3 times that of GonaContreated deer (Fisher's exact test, $P<0.001$ ).

During summer 2007, 13 (57\%) of 23 GonaCon-treated females and 10 (83\%) of 12 control females lactated (Table 1). Necropsy observations in October 2007 confirmed the lactational status of these deer, except female number 14, who had stopped lactating by October. Although the pregnancy rate among control deer during 2007 was more than $45 \%$ higher than that of GonaCon-treated deer, the difference was not significant (Fisher's exact test, $P=0.112$ ).

Anti-GnRH antibody titers ranged from $0(n=2)$ to 1:128,000 $(n=5)$ in GonaCon-treated adult females 2 years after treatment. Fifteen (83\%) of the 18 vaccinated adult female deer we evaluated had titers $\geq 1: 16,000$, including 3 females that were given booster injections during the field study (deer no. 17 and 29 in Oct 2006, and deer no. 16 in Jun 2007, all of which had antibody titers of 1:128,000). All 12 control females had titers of 0 .

Both ovaries were small and inactive in 8 (31\%) of 26 adult deer at necropsy in October 2007; 7 of these 8 deer had been injected with GonaCon, and 6 of the 7 vaccinates had not lactated during 2006 or 2007. (Two of these 7 deer had received booster injections after summer 2006.) Ovaries of all but one control deer were normal in size and contained small follicles. Uterine size was within normal limits at necropsy in all 16 examined GonaCon-treated adult females and in 9 of 10 examined control adult females.

\section{Fawns (Females, 8 Months Old)}

Of the 4 female fawns treated in February 2006, 1 left the study site soon after vaccination and did not return. None of the other 3 lactated as a yearling in 2006. Two did not lactate as 2-year-olds in 2007; only 1 of these 2 deer (no. 76) was necropsied in 2007 and it had small, inactive ovaries, an enlarged uterus, and an anti-GnRH antibody titer of 1:128,000. The third deer (no. 78) lactated in 2007 and had normal ovaries with small follicles, a small, inactive uterus, and an antibody titer of 1:64,000.

\section{Fawns (Females and Males, 3-4 Months Old)}

Of the 8 female fawns treated in September-October 2006, 2 died of unknown causes before summer 2007. The remaining 6 females did not lactate as yearlings during summer 2007. Five of these 6 females were collected in October 2007, when they had anti-GnRH antibody titers ranging from 0 to 1:64,000. Necropsies of 4 of these deer revealed that ovaries were small and/or inactive at necropsy in 2 deer, and ovaries contained small follicles in 2 other deer. Two of these 4 deer had small, inactive uteri (one had small ovaries and one had normal ovaries with small follicles).

Seven of the 8 males treated as 3-4-month-old fawns survived to the end of the study and were collected and necropsied in October 2007. Testicular circumferences and serum testosterone concentrations did not differ between these males and control yearling males (circumferences: $t_{5}=1.75, P=0.070$; testosterone: $\left.t_{7}=0.01, P=0.494\right)$, or between these males and GonaCon-treated adult males (circumferences: $t_{7}=-1.01, \quad P=0.172 ;$ testosterone: $\left.t_{5}=-1.70, P=0.073\right)$.

\section{Adult Males}

Of 10 yearling and adult males treated during March 2007, 2 died of unknown causes and 2 left the study site before October 2007. One of the deer that left the site was observed with large, normal-appearing antlers during late June 2007. Four of the 6 males that remained on site had normal, hardened antlers, and testes of normal size $(16.0-19.5 \mathrm{~cm}$ in circumference). In contrast, 2 others had antlers that were still in velvet and smaller testes (2-sample $t$-test, $t_{3}=-10.55, P<0.001$; testicular circumferences: $9.0 \mathrm{~cm}$ and $9.5 \mathrm{~cm}$ ). Overall, however, mean testicular circumferences did not differ $\left(t_{5}=-1.43, P=0.102\right)$ between males treated as adults in March 2007 and a group of control adults. Mean serum testosterone concentrations also did not differ $\left(t_{9}=-0.13, P=0.449\right)$ between these 2 groups. Anti$\mathrm{GnRH}$ antibody titers were consistently low $(\leq 1: 8,000)$ in males that had hardened antlers, normal testes, and moderate testosterone levels, and they were consistently high $(\geq 1: 32,000)$ in males that had antlers retaining velvet, small testes, and relatively low testosterone levels.

\section{Control Males}

Thirteen previously untreated males were collected for necropsy during October 2007 for comparison (see above) with GonaCon-treated males. Nine were adults with antlers nor$\mathrm{mal}$ in appearance and scrotal circumferences ranging from $15.5 \mathrm{~cm}$ to $20.0 \mathrm{~cm}$. The other 4 males were yearlings with normal spiked $(n=3)$ or button $(n=1)$ antlers. All antlers lacked velvet and had hardened. Testicular circumferences in control yearlings ranged from $13.5 \mathrm{~cm}$ to $17.0 \mathrm{~cm}$ and did not differ $\left(t_{3}=-1.42, P=0.126\right)$ from those of control adults. Serum testosterone concentrations were lower in control yearlings than adults $\left(t_{7}=-2.55, P=0.018\right)$. Anti-GnRH antibody titers were not measured, but were assumed to be 0 in these noninjected males.

\section{DISCUSSION}

\section{Induced Infertility in Female Deer}

GonaCon Immunocontraceptive Vaccine induced temporary infertility in a large proportion of treated adult female whitetailed deer. The strength and duration of immune responses to immunocontraceptive treatment varied among treated individuals in this study and in previous studies (Miller et al. 2008a; Gionfriddo et al. 2009). In the current study, $67 \%$ of GonaCon-treated adult female white-tailed deer were infertile 1 year after vaccination, and $43 \%$ were infertile after 2 years. In a similar field study in Maryland, $88 \%$ of GonaCon-treated white-tailed females were infertile after 1 year, and $47 \%$ were infertile after 2 years (Gionfriddo et al. 2009). Captive adult female white-tailed deer $(n=5)$ treated with GonaCon at Pennsylvania State University remained infertile for 2 years, and 4 of 5 deer were infertile 5 years after treatment (Miller et al. 2008a). Six of 10 captive adult female black-tailed deer (Odocoileus hemionus hemionus) in Washington State, USA, were infertile for 3 years after 
each received an injection of GonaCon vaccine (Perry et al. 2008).

Treatment of young (3-4-month-old) female fawns in our study did not induce a strong, sustained immune response required for contraception, a finding supported by Miller et al. (2008b). This result suggests that the immune systems of fawns may be insufficiently mature for immunocontraception, and that operational treatment of deer with GonaCon vaccine should focus on adult females. Nonetheless, experimental treatment of fawns to determine contraceptive efficacy is important because future wildlife contraceptive agents could be delivered orally, and treated bait may be consumed by deer of all ages.

The level of circulating anti-GnRH antibodies is a good indicator of the fertility status of an animal treated with an immunocontraceptive agent (McShea et al. 1997). Other than infertility, no side effects are associated with the presence of antibodies against GnRH (Delves 2002). In most treated animals, fertility is naturally regained after a decline in antibody titers (Keeling and Crighton 1984).

The immune response must reach and maintain a threshold level for contraception to occur (Adams and Adams 1990, Zeng et al. 2002). In white-tailed deer, infertility is normally associated with anti-GnRH antibody titers $\geq 1: 64,000$ (Miller et al. 2000, 2008a; Gionfriddo et al. 2009). In the current study, 27 months after vaccination, titers were $\geq 1: 64,000$ in 4 (29\%) of 14 nonboosted GonaCon-treated adult females, all of which were infertile in 2006 and 2007. Of the 5 examined females that were vaccinated in September-October 2006 as 3-4-month-old fawns, 1 (20\%) had a titer $\geq 1: 64,000$. Although these 5 deer were vaccinated too late in the 2006-2007 reproductive cycle to affect reproduction that year, they were likely too young to breed until (at least) autumn 2007. Both of the females that had been vaccinated at 8 months of age and remained alive on the study site had titers $\geq 1: 64,000$, although one of them was pregnant in 2007.

Severe overbrowsing was evident throughout the study area when the study began. Most deer captured in July 2005 were noticeably thin, with body masses estimated at $32-57 \mathrm{~kg}$. Healthy adult female white-tailed deer in the northeastern United States generally weigh 41-96 kg (Whitaker and Hamilton 1998). Fat reserves in study deer at necropsy in 2007 were generally meager (Gionfriddo et al. 2011). The relationship between nutrition and immune response has long been recognized (Homsy et al. 1986, Chandra and Amorin 1992), and it is possible that stronger immune responses (and greater contraceptive efficacy) may have been achieved if study deer had been in better physical condition. As a practical matter, however, most overabundant deer populations that would be candidates for treatment with contraceptive agents would likely have experienced suboptimal nutrition.

Small and inactive ovaries and uteri, as observed in many of the GonaCon-treated females in this study, are commonly associated with $\mathrm{GnRH}$ immunocontraception and are indicators of successful contraception. GonaCon induces the production of anti-GnRH antibodies that bind to endoge- nous $\mathrm{GnRH}$ and prevent the release of luteinizing hormone (LH) and follicle-stimulating hormone (FSH) from the anterior pituitary gland. In the absence of $\mathrm{LH}$ and FSH, the gonads remain quiescent, production of sex hormones is sharply reduced, and the animal remains in a nonreproductive state.

The administration of booster vaccine injections to several of our adult female study deer provided an opportunity to evaluate the effect of such injections on contraceptive efficacy. For example, females numbered 17 and 29 were each given a $1.0-\mathrm{mL}$ booster injection of GonaCon in October 2006 after lactating during summer 2006. Neither female lactated in 2007; both females had very high anti-GnRH antibody titers $(1: 128,000)$ when collected in October 2007, suggesting that the booster injections had stimulated strong immune responses. Deer number 28 followed a similar pattern. After her pregnancy in summer 2006, she was boosted in October and then did not lactate in 2007. Unfortunately her carcass was too badly decomposed when it was found in September 2007 to permit blood collection or necropsy examination. In contrast to these examples, a booster injection did not seem to be effective in deer number 5 . She lactated in summer 2006, was boosted in October 2006, and lactated again in 2007. Her antibody titer was 1:32,000 in October 2007. Booster vaccine injections seem to increase or extend contraceptive efficacy in some, but not all, cases.

\section{Responses of Male Deer to Vaccination}

Although mean values for testicular circumferences and serum testosterone concentrations did not differ between GonaCon-treated and control males, vaccination with GonaCon affected reproductive parameters in some adult males (no. 81 and 82 ), which, 12 months after vaccination, had small testes, negligible testosterone concentrations, and antlers that retained velvet into October. In contrast, treated adult males 87, 88, and 90 had "normal" values for these parameters when compared with control adult males. AntiGnRH antibody titers in males treated with GonaCon as 34-month-old fawns were similar to those of same-aged females and support the hypothesis that immunocontraception of young fawns may not be feasible.

In our study, deer were collected for necropsy in early October when testosterone concentrations normally increase as the rut approaches (Mirarchi et al. 1977). Treatment with GonaCon vaccine typically reduces the production of testosterone and growth of testes (Killian et al. 2005), and produces males that resemble morphological castrates. Thus it was not surprising that 2 treated deer had smaller testes and lower testosterone concentrations than untreated deer. Curtis et al. (2008) reported similar results for free-ranging male white-tailed deer treated with $\mathrm{GnRH}$ vaccines. We agree with Killian et al. (2005) and Curtis et al. (2008) that male deer should not be treated with $\mathrm{GnRH}$ vaccines because of potential social consequences for treated individuals.

\section{MANAGEMENT IMPLICATIONS}

Successful management of overabundant suburban deer populations requires an initial reduction in numbers to a desired 
density, and then maintenance of that density (Merrill et al. 2006). Contraceptive efficacy rates demonstrated for GonaCon vaccine in New Jersey support the contention that the most efficient approach to managing overabundant suburban deer populations may be to combine culling (for initial population reduction) and contraception (for population stabilization; Bomford 1990, Hobbs et al. 2000). Once deer numbers have been reduced to a desired level, population stability can be achieved by preventing about $60-80 \%$ of the breeding females from reproducing each year (Garrott 1995, McCullough 1996). Such levels of infertility should be achievable through rigorous application of GonaCon vaccine. Timely reduction of overabundant deer populations using contraception alone, however, is not feasible at current efficacy rates.

The need for safe, effective, practical, and humane wildlife contraceptive agents to manage overabundant wildlife populations in situations where traditional management methods cannot be applied will continue to drive the development of contraceptive products. Immunocontraception of whitetailed deer shows promise as a tool for stabilizing demographically closed populations, but improvements may be needed if this technology is to be accepted and applied widely in real-world settings by natural resource professionals. Greater contraceptive efficacy (i.e., a higher proportion of treated animals rendered infertile and a longer duration of contraceptive effect) is a goal of ongoing research.

\section{ACKNOWLEDGMENTS}

We are very grateful to S. F. Timm for field necropsies, C. A. Yoder for help with statistics, R. Rodts, D. Cuddy, V. DeNicola, and C. Collier for field assistance, and K. A. Crane, J. M. Kemp, C. M. Denny, and L. E. O'Dell for laboratory assistance. We thank Associate Editor Nielsen and 2 anonymous reviewers for comments that improved the manuscript.

\section{LITERATURE CITED}

Adams, T. E., and B. M. Adams. 1990. Reproductive function and feedlot performance of beef heifers actively immunized against $\mathrm{GnRH}$. Journal of Animal Science 68:2793-2802.

Balser, D. S. 1964. Management of predator populations with antifertility agents. Journal of Wildlife Management 28:352-358.

Bomford, M. 1990. A role for fertility control in wildlife management? Bureau of Rural Resources Bulletin 7, Canberra, Australia.

Chandra, R. K., and S. A. D. Amorin. 1992. Lipids and immunoregulation. Nutrition Research 12:S137-S145.

Crête, M., and C. Daigle. 1999. Management of indigenous North American deer at the end of the 20th century in relation to large predators and primary productivity. Acta Veterinaria Hungarica 47:1-16.

Curtis, P. D., M. E. Richmond, L. A. Miller, and F. W. Quimby. 2008. Physiological effects of gonadotropin-releasing hormone immunocontraception on white-tailed deer. Human-Wildlife Conflicts 2:35-46.

Davis, D. E. 1961. Principles for population control by gametocides. Transactions of the North American Wildlife Conference 26:160-166.

Delves, P. J. 2002. The development of contraceptive vaccines. Expert Opinion on Investigational Drugs 11:1225-1237.

Etter, D. R., T. R. Van Deelen, D. R. Ludwig, S. N. Kobal, and R. E. Warner. 2000. Management of white-tailed deer in Chicago, Illinois forest preserves. Proceedings of the Vertebrate Pest Conference 19: 190-196.
Fagerstone, K. A., M. A. Coffey, P. D. Curtis, R. A. Dolbeer, G. J. Killian, L. A. Miller, and L. M. Wilmot. 2002. Wildlife fertility control. Wildlife Society Technical Review 02-2. The Wildlife Society, Bethesda, Maryland, USA.

Fagerstone, K. A., L. A. Miller, G. J. Killian, and C. A. Yoder. 2010. Review of issues concerning the use of reproductive inhibitors, with particular emphasis on resolving human-wildlife conflicts in North America. Integrative Zoology 1:15-30.

Farwell, K. 2009. GonaCon ${ }^{\text {TM }}$ Immunocontraceptive Vaccine for use in white-tailed deer. Section 3 Registration. U.S. Environmental Protection Agency, Office of Pesticide Programs, Memorandum from Health Effects Division to Insecticide/Rodenticide Branch, 4 Aug 2009.

Garrott, R. A. 1995. Effective management of free-ranging ungulate populations using contraception. Wildlife Society Bulletin 23:445-452.

Gionfriddo, J. P., J. D. Eisemann, K. J. Sullivan, R. S. Healey, L. A. Miller, K. A. Fagerstone, R. M. Engeman, and C. A. Yoder. 2009. Field test of a gonadotrophin-releasing hormone immunocontraceptive vaccine in female white-tailed deer. Wildlife Research 36:177-184.

Gionfriddo, J. P., A. J. DeNicola, L. A. Miller, and K. A. Fagerstone. 2011. Health effects of $\mathrm{GnRH}$ immunocontraception of wild white-tailed deer in New Jersey. Wildlife Society Bulletin 35:149-160.

Hobbs, N. T., D. C. Bowden, and D. L. Baker. 2000. Effects of fertility control on populations of ungulates: general, stage-structured models. Journal of Wildlife Management 64:473-491.

Homsy, J., W. J. W. Morrow, and J. A. Levy. 1986. Nutrition and autoimmunity: a review. Clinical Experimental Immunology 65:473-488.

Keeling, B. J., and D. B. Crighton. 1984. Reversibility of the effects of active immunization against LH-RH. Pages 379-398 in D. B. Crighton, editor. Immunological aspects of reproduction in mammals. Butterworths, London, United Kingdom.

Killian, G. J., D. Wagner, and L. A. Miller. 2005. Observations on the use of the $\mathrm{GnRH}$ vaccine GonaCon in male white-tailed deer (Odocoileus virginianus). Proceedings of the Wildlife Damage Management Conference 11:256-263.

Lauber, T. B., and B. A. Knuth. 2000. Suburban residents' criteria for evaluating contraception and other deer management techniques. Human Dimensions of Wildlife 5:1-17.

McCullough, D. R. 1996. Demography and management of wild populations by reproductive intervention. Pages 119-132 in P. N. Cohn, E. D. Plotka, and U. S. Seal, editors. Contraception in wildlife. Book 1. Edwin Mellen, Lewiston, New York, USA.

McShea, W. J., S. L. Monfort, S. Hakim, J. Kirkpatrick, I. Liu, J. W. Turner, Jr., L. Chassy, and L. Munson. 1997. The effect of immunocontraception on the behavior and reproduction of white-tailed deer. Journal of Wildlife Management 61:560-569.

McShea, W. J., and J. H. Rappole. 2000. Managing the abundance and diversity of breeding bird populations through manipulation of deer populations. Conservation Biology 14:1161-1170.

Merrill, J. A., E. G. Cooch, and P. D. Curtis. 2006. Managing an overabundant deer population by sterilization: effects of immigration, stochasticity and the capture process. Journal of Wildlife Management 70:268-277.

Miller, L. A., J. P. Gionfriddo, K. A. Fagerstone, J. C. Rhyan, and G. J. Killian. 2008a. The single-shot $\mathrm{GnRH}$ immunocontraceptive vaccine $\left(\mathrm{GonaCon}{ }^{\mathrm{TM}}\right)$ in white-tailed deer: comparison of several $\mathrm{GnRH}$ preparations. American Journal of Reproductive Immunology 60:214223.

Miller, L. A., J. P. Gionfriddo, J. C. Rhyan, K. A. Fagerstone, D. C. Wagner, and G. J. Killian. 2008b. GnRH contraception of male and female white-tailed deer fawns. Human-Wildlife Conflicts 2:93-101.

Miller, L. A., B. E. Johns, and G. J. Killian. 2000. Immunocontraception of white-tailed deer with GnRH vaccine. American Journal of Reproductive Immunology 44:266-274.

Miller, L. A., J. C. Rhyan, and G. J. Killian. 2004. GonaCon ${ }^{\text {TM }}$, a versatile GnRH contraceptive for a large variety of pest animal problems. Proceedings of the Vertebrate Pest Conference 21:269-273.

Mirarchi, R. E., P. F. Scanlon, and R. L. Kirkpatrick. 1977. Annual changes in spermatozoan production and associated organs of white-tailed deer. Journal of Wildlife Management 41:92-99.

Muller, L. I., R. J. Warren, and D. L. Evans. 1997. Theory and practice of immunocontraception in wild animals. Wildlife Society Bulletin 25:504514. 
Munson, L., compiler. 2010. Necropsy of wild animals. <http://www. vetmed.ucdavis.edu/whe/pdfs/necropsy.pdf $>$. Accessed 1 Apr 2011.

Perry, K. R., L. A. Miller, and J. Taylor. 2008. Mycobacterium avium: is it an essential ingredient for a single-injection immunocontraceptive vaccine? Proceedings of the Vertebrate Pest Conference 23:253256.

Pojar, T. M., and D. C. Bowden. 2004. Neonatal mule deer fawn survival in west-central Colorado. Journal of Wildlife Management 68:550560.

Rooney, T. P., and D. M. Waller. 2003. Direct and indirect effects of whitetailed deer in forest ecosystems. Forest Ecology and Management 181: 165-176.

Stout, R. J., B. A. Knuth, and P. D. Curtis. 1997. Preferences of suburban landowners for deer management techniques: a step towards better communication. Wildlife Society Bulletin 25:348-359.
Vandenbergh, J. G., and D. E. Davis. 1962. Gametocidal effects of triethylenemelamine on a breeding population of red-winged blackbirds. Journal of Wildlife Management 26:366-371.

Whitaker, J. O., Jr., and W. J. Hamilton, Jr. 1998. Mammals of the eastern United States. Third edition. Comstock, Ithaca, New York, USA.

Whitten, K. R. 1995. Antler loss and udder distention in relation to parturition in caribou. Journal of Wildlife Management 59:273-277.

Zeng, X. Y., J. A. Turkstra, A. Tsigos, R. H. Meloen, X. Y. Liu, F. Q. Chen, W. M. M. Schaaper, H. B. Oonk, D. Z. Guo, and D. F. M. van de Wiel. 2002. Effects of active immunization against $\mathrm{GnRH}$ on serum $\mathrm{LH}$, inhibin A, sexual development and growth rate in Chinese female pigs. Theriogenology 58:1315-1326.

Associate Editor: Nielsen. 